\section{Maternale Immunisierung zum Schutz von Neugeborenen}

\begin{abstract}
$\mathrm{D}$ ie ESPID-Jahrestagung bietet Einblicke in die Impfstrategien unserer Nachbarländer, die je nach Prävalenz und Finanzierungsstrukturen unterschiedlich ausfallen. Bei Keuchhusten werden in Wellenbewegungen immer wieder Ausbrüche beobachtet. In Großbritannien entschied man sich bei der Pertussis-Impfung für ein temporäres Impfprogramm für werdende Mütter, nachdem im Jahr 201214 Kinder unter drei Monaten an Pertussis verstorben waren. Die Frauen erhielten am Ende der Schwangerschaft einen Vierfach-Impfstoff (Diphtherie, Tetanus, Pertussis, Polio), um zur Geburt möglichst hohe Titer maternaler Antikörper zu erzielen. Mit einer breiten Abdeckung von über $60 \%$ konnte die Rate der Infektionen gesenkt
\end{abstract}

werden. Die Pertussis-Impfung während der Schwangerschaft gilt als beste Strategie, Neugeborene vor einer Infektion zu schützen, erläuterte Dr. Gayatri Amirthalingam, Public Health England, London. Geimpfte Mütter fallen auch als Infektionsquelle aus. Die Engländer untersuchen aktuell, ob maternale Antikörpertiter die Impferfolge in der anschließenden Routineimpfung der Säuglinge beeinflussen, um Zeitpläne entsprechend anpassen zu können.

Zum Schutz von Schwangeren und Neugeborenen empfiehlt auch die WHO unter gewissen Umständen die maternale Immunisierung. Die Impfung von Schwangeren ist in der aktuellen Indikation der in Deutschland verfügbaren Pertussis-Impfstoffe nicht enthalten.
Die Sicherheit eines Vierfach-Impfstoffes und einer Influenza-Vakzine in der Schwangerschaft wurde auch durch eine beim ESPID präsentierte spanische Studie belegt. Die Influenza-Impfung wird auch in Deutschland für werdende Mütter von der STIKO empfohlen.

Die maternale Immunisierung könnte auch ein Ansatz zur RSV-Impfung sein und wird derzeit in Studien untersucht: Der Hersteller einer RSV-NanopartikelVakzine präsentierte Phase-II-Daten, mit der perinatalen Infektionen mit dem Respiratory Syncytial Virus vorgebeugt werden sollen. Mit weiteren Studien und der Entwicklung neuer Impfstoffe werden die Optionen für maternale Impfkampagnen in Zukunft wohl größer werden.

Martina Freyer

Amirthalingam G. Pertussis - strategies for protecting the most vulnerable children

\section{Kinder auf der Flucht: die Erfahrungen der Münchner Pädiater}

$\mathrm{D}$ ie große Anzahl an Flüchtlingen, die im September 2015 am Münchner Hauptbahnhof ankamen, stellte mit einem Tagesmaximum von 13.000 Menschen auch Pädiater vor große Herausforderungen. Bei der Ankunft wurden Kinder und Jugendliche mit Unterstützung von Freiwilligen-Organisationen wie den Refudocs e. V. versorgt. Dr. Ulrich von Both vom Dr. von Haunerschen Kinderspital in München berichtete, dass neben gängigen Infektionserkrankungen auch einige Fälle von Lungentuberkulose, Skabies, Malaria, Schistosomiasis und HIV diagnostiziert wurden. Die Mediziner wurden auch mit ungewöhnlichen Erkrankungen wie dem Läuserückfallfieber konfrontiert, das meist aus Ostafrika stammte. Hier kann nach Erfahrungsberichten der Helfer das Entsorgen der mit Läusen befallenen Bekleidung die weitere Verbreitung einfach durchbrechen.

Beim Begriff des „Datenaustauschverbesserungsgesetzes“, mit dem die Registrierung von Flüchtlingen erleichtert werden soll, verstanden auch englisch- sprachige Zuhörer, dass die medizinische Versorgung mit bürokratischen Hürden verknüpft ist.

Hier erfordern ungewöhnliche Situationen ungewöhnliche Lösungsansätze verschiedener Player im Gesundheitswesen: Von Both beschrieb am Beispiel der Tuberkulose, wie ein Runder Tisch vieler Beteiligter im Münchner Raum mit Kliniken, Universitäten und Gesundheitsministerium - eine problemorientierte Zusammenarbeit erleichterte und Empfehlungen für ein Tuberkulose-Screening für alle Asylsuchende unter 15 Jahren erarbeitete. Er betonte, dass die im letzten Herbst entwickelten Empfehlungen auch wissenschaftlich begleitet und validiert werden müssten. Nur so könne man aus den Erfahrungen lernen, um sich in Zukunft besser auf vergleichbare Ereignisse vorbereiten zu können.

Martina Freyer

von Both U. Refugees arriving in Europe: the Munich pediatric infection experience

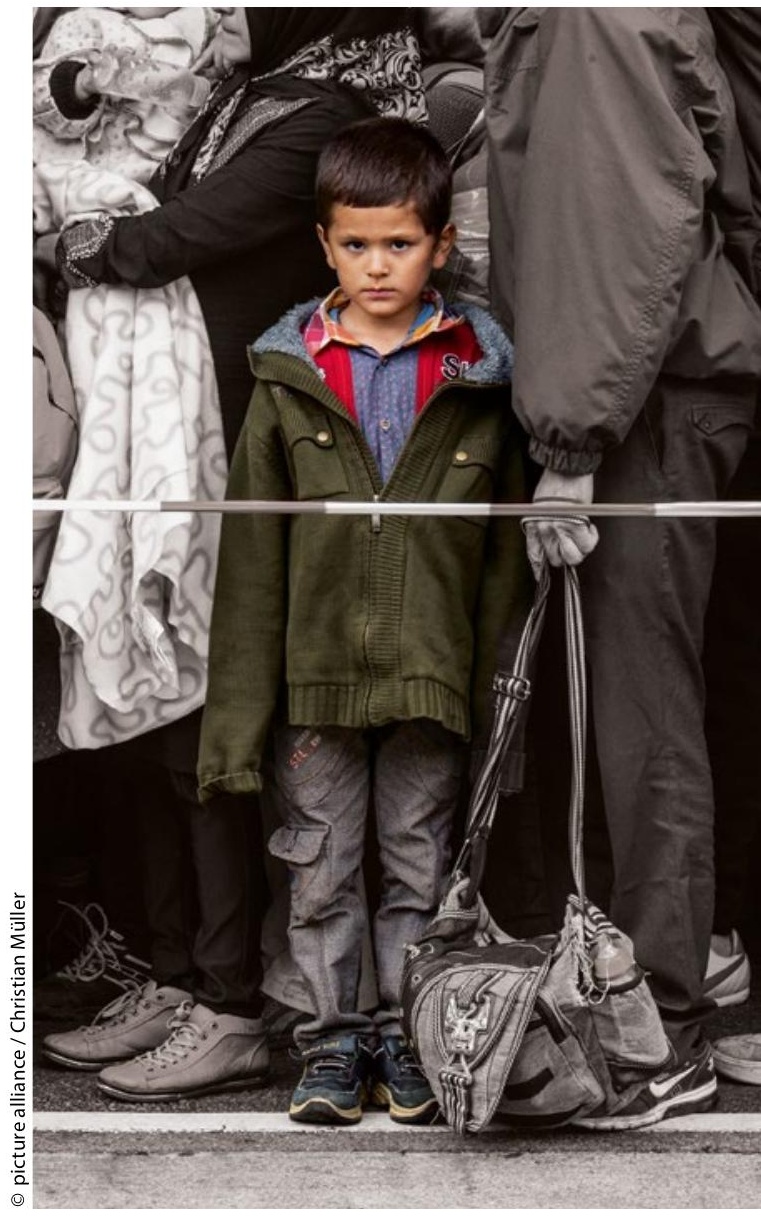

